\title{
AREG mediates the epithelial-mesenchymal transition in pancreatic cancer cells via the EGFR/ERK/NF-кB signalling pathway
}

\author{
LI WANG $^{1,2}$, LILI WANG ${ }^{1}$, HUI ZHANG ${ }^{1}$, JUNLIANG LU ${ }^{1}$, ZHIWEN ZHANG ${ }^{1}$, \\ HUANWEN WU ${ }^{1}$ and ZHIYONG LIANG ${ }^{1}$
}

\begin{abstract}
${ }^{1}$ Department of Pathology, Peking Union Medical College Hospital, Research Center for Molecular Pathology, Chinese Academy of Medical Sciences and Peking Union Medical College, Beijing 100730; ${ }^{2}$ Department of Pathology, Tongji Hospital, Tongji Medical College, Huazhong University of Science and Technology, Wuhan, Hubei 430030, P.R. China
\end{abstract}

Received August 11, 2019; Accepted January 21, 2020

DOI: $10.3892 /$ or.2020.7523

\begin{abstract}
Amphiregulin (AREG) is a member of the epidermal growth factor (EGF) family and is expressed in a plethora of cancers. The biological roles of AREG in the regulation of the epithelial-mesenchymal transition (EMT) in pancreatic cancer remain unclear. To investigate the expression of epidermal growth factor receptor (EGFR) and AREG in pancreatic cancer cell lines, RT-qPCR, western blot analysis, and ELISA were performed. RNAi and exogenous AREG treatment were used to alter AREG expression. Wound-healing and Transwell assays were performed to evaluate cell migration and invasion abilities. Western blot analysis and immunofluorescence staining were utilized to detect the expression of EMT markers. The protein expression of potential key factors involved in EMT, as well as those of the ERK, AKT, STAT3 and NF- $\mathrm{BB}$ pathways, were analysed by western blotting. The role of AREG in tumour growth in vivo was further determined using an orthotopic model of pancreatic cancer. Knockdown of AREG inhibited AsPC-1 cell migration and invasion. AREG knockdown upregulated E-cadherin but downregulated vimentin, Snail and Slug expression in AsPC-1 cells. In addition, AREG stimulation increased cell migration, invasion and EMT in PANC-1 cells, and an NF- $\kappa \mathrm{B}$ inhibitor decreased AREG-induced cell migration, invasion and EMT in PANC-1 cells. AREG stimulation increased the nuclear accumulation of NF- $\kappa \mathrm{B}$ through the EGFR/ERK signalling pathway to induce EMT. Tumour growth and metastasis were
\end{abstract}

Correspondence to: Dr Huanwen Wu or Professor Zhiyong Liang, Department of Pathology, Peking Union Medical College Hospital, Research Center for Molecular Pathology, Chinese Academy of Medical Sciences and Peking Union Medical College, 1 Shuaifuyuan, Dongcheng, Beijing 100730, P.R. China

E-mail: whw14093@163.com

E-mail: liangzhiyong1220@yahoo.com

Key words: AREG, pancreatic cancer, EMT, ERK, NF-кB decreased by AREG silencing in an orthotopic model of pancreatic cancer. AREG may play a critical role in cell migration, invasion, and EMT by activating the EGFR/ERK/NF- $\kappa \mathrm{B}$ signalling pathway in pancreatic cancer cells.

\section{Introduction}

Pancreatic cancer is one of the leading causes of cancer-related mortality worldwide, and the 5-year survival rate is less than $9 \%$; more than $50 \%$ of cases are diagnosed at an advanced stage, which partially explains the low survival rate (1). The high mortality rate among advanced pancreatic cancer patients is linked to their limited response to chemotherapy and radiotherapy. The epithelial-mesenchymal transition (EMT) phenotype is a critical mediator of drug resistance in pancreatic cancer patients (2). The activation of the EMT process has been proposed as the critical mechanism responsible for the acquisition of drug resistance in pancreatic cancer cells $(3,4)$. Furthermore, EMT has been revealed to contribute to the invasion and metastasis of various types of carcinomas, including pancreatic cancer (5-7). However, the vital role of EMT in cancer invasion and metastasis has been recently challenged based on murine studies $(8,9)$.

Amphiregulin (AREG) is a member of the epidermal growth factor (EGF) family and is expressed in a plethora of neoplasms, including ovarian, breast, bladder, colon, lung, major salivary glands and pancreatic cancers (10-16). AREG interacts with epidermal growth factor receptor (EGFR) to trigger numerous signalling cascades that mediate cell survival, proliferation, and motility. According to studies investigating ovarian cancer (10), and breast cancer (11), AREG plays a crucial role in cell invasion and metastasis. AREG was linked to a reduced life span in bladder cancer (12) and lung cancer patients (13). However, AREG overexpression was associated with a longer disease-free survival in colorectal cancer (14) and mucoepidermoid carcinoma patients (15). In our previous study, it was revealed that AREG expression was correlated with a poor prognosis in pancreatic cancer patients (16). To date, knowledge regarding the molecular mechanisms underlying AREG-induced migration, invasion and EMT in 
pancreatic cancer cells is limited. The aim of this study was to detect the molecular mechanism of AREG mediating EMT in pancreatic cancer cells in vitro and in vivo.

\section{Materials and methods}

Cell culture. Four human pancreatic cancer cell lines, PANC-1 (cat. no. CRL-1469), AsPC-1 (cat. no. CRL-1682), BxPC-3 (cat.no. CRL-1687) and MIA PaCa-2 (cat. no. CRL-1420) were purchased from American Type Culture Collection (ATCC). The cell lines (PANC-1, AsPC-1, BxPC-3 and MIA PaCa-2) had been identified by specialized STR profiling and tested for mycoplasma contamination. PANC-1 and MIA PaCa-2 were maintained in Dulbecco's Modified Eagle's Medium (DMEM), while AsPC-1 and BxPC-2 were maintained in RPMI-1640 medium (both from Corning Incorporated). The medium was supplemented with $10 \%$ fetal bovine serum (FBS; Gibco; Thermo Fisher Scientific, Inc.), 1\% penicillin/streptomycin and $1 \mathrm{mM}$ glutamine (Invitrogen; Thermo Fisher Scientific, Inc.). The cells were grown in $5 \% \mathrm{CO}_{2}$ at $37^{\circ} \mathrm{C}$ in a humidified atmosphere.

Antibodies and reagents. EMT Antibody Sampler Kit (cat. no. 9782), NF-кB pathway Sampler Kit (cat. no. 9936), Phospho-EGF Receptor Antibody Sampler Kit (cat. no. 9922) and anti-phospho-STAT3 (cat. no. 9145) antibody were purchased from Cell Signaling Technology, Inc., except for anti-ERK (cat. no. sc-154) and anti-phospho-ERK (cat. no. sc-7976-R), anti-AKT (cat. no. sc-81434) and anti-phospho-AKT (cat. no. sc-81433) and anti-STAT3 (cat. no. sc-482) antibodies (Santa Cruz Biotechnology, Inc.). The recombinant human AREG protein (cat. no. 262-AR-100) and normal goat IgG control (cat. no. AB-108-C) were purchased from R\&D Systems. PD153035 (EGFR tyrosine kinase inhibitor), U0126 (MEK1/2 inhibitor) and QNZ (NF- $\mathrm{KB}$ inhibitor) were purchased from Selleckchem. PD153035, U0126 and QNZ were dissolved in dimethyl sulphoxide (DMSO) and maintained at $-20^{\circ} \mathrm{C}$ until use. AREG and IgG were dissolved in sterile PBS containing 0.1\% FBS just before use.

Preparation of conditioned medium. The cells were grown to $80-90 \%$ confluence in $25-\mathrm{cm}^{2}$ flasks and then rinsed three times with serum-free medium. Then, the cells were incubated with serum-free medium for $48 \mathrm{~h}$. The conditioned medium was harvested and centrifuged $\left(335 \mathrm{x} \mathrm{g}\right.$ for $\left.10 \mathrm{~min}, 4^{\circ} \mathrm{C}\right)$. After centrifugation, the supernatant was collected and stored at $-80^{\circ} \mathrm{C}$ for the subsequent enzyme-linked immunosorbent assay (ELISA).

Quantitative real-time PCR. Detailed procedures for total RNA extraction and RT-qPCR have been previously described (17). The primer sequences were as follows: AREG, 5'-TGAGAT GTCTTCAGGGAGTG-3' (sense) and 5'-AGCCAGGTATTT GTGGTTCG-3' (antisense); EGFR, 5'-GGATGCCGACGA GTACCTC-3' (sense) and 5'-GCTTTGCAGCCCATTTCT AT-3' (antisense); and glyceraldehyde-3-phosphate dehydrogenase (GAPDH), 5'-GGCATCCTGGGCTACACTG-3' (sense) and 5'-GTGGTCGTTGAGGGCAAT-3' (antisense). GAPDH was used as a control. The mRNA levels were analysed using the comparative quantification cycle $(\mathrm{Cq})$ method $\left(2^{-\Delta \Delta \mathrm{Cq}}\right)(18)$.
Western blot analysis. Western blot analysis was performed as previously described (17). Dilution rates for all primary and secondary antibodies were 1:1,000 and 1:10,000, respectively. The blots were probed with ECL Plus Western Blotting Detection kit (Pierce Biotechnology; Thermo Fisher Scientific, Inc.). The densities of the bands were scanned and analysed using ImageJ software (version $1.48 \mathrm{v}$; National Institutes of Health).

ELISA. The secretion level of AREG was assessed using an AREG ELISA kit (cat. no. DAR00; R\&D systems) according to the manufacturer's instructions.

RNA interference. The siRNAs targeting AREG were as follows: AREG-Homo-390 (siAR-390), 5'-GGAUUUGAG GUUACCUCAATT-3' (sense) and 5'-UUGAGGUAACCU CAAAUCCTT-3' (antisense); AREG-Homo-817 (siAR-817), 5'-GCAUGAUUGACAGUAGUUUTT-3' (sense) and 5'-AAACUACUGUCA AUCAUGCTT-3' (antisense); and AREG-Homo-348 (siAR-348), 5'-UCUGGGAAGCGU GAACCAUTT-3' (sense) and 5'-AUGGUUCACGCUUCC CAGATT-3' (antisense). The siRNA control sequences were 5'-UUCUCCGAACGUGUCACGUTT-3' (sense) and 5'-ACG UGACACGUUCGGAGAATT-3' (antisense). All siRNAs were purchased from Shanghai GenePharma Co., Ltd. AREG was transfected into AsPC-1 cells in 6-well plates using Lipofectamine RNAiMAX Reagent (Invitrogen; Thermo Fisher Scientific, Inc.). Total protein and RNA were extracted, and the knockdown efficiency of AREG was verified by western blotting and RT-qPCR analyses, respectively.

Immunofluorescence. AsPC-1 cells were transfected with AREG siRNA (siAR-390) or control siRNA (NC) for $48 \mathrm{~h}$. PANC-1 cells were treated with AREG (100 ng/ml, AREG), or normal $\mathrm{IgG}(100 \mathrm{ng} / \mathrm{ml}, \mathrm{NC})$ for $48 \mathrm{~h}$. A total of $2 \times 10^{5}$ cells were seeded on coverslips. After $24 \mathrm{~h}$, serum-free culture medium was removed from each well and replaced with $4 \%$ paraformaldehyde, and the plates were incubated for $15 \mathrm{~min}$ at room temperature for fixation. Then, the cells were washed with PBS three times. After blockade of non-specific epitopes by $10 \%$ normal goat serum for $1 \mathrm{~h}$ at room temperature, primary antibodies against E-cadherin (1:100 dilution; cat. no. 3195; Cell Signaling Technology, Inc.) or vimentin (1:200 dilution; cat. no. 5741; Cell Signaling Technology, Inc.) were added. After overnight incubation at $4{ }^{\circ} \mathrm{C}$, the primary antibody was washed by rinsing three times with PBS, followed by incubation of secondary antibodies (Alexa Fluor ${ }^{\circledR} 488$ Conjugate, cat. no. 4412 or Alexa Fluor ${ }^{\circledR} 594$ Conjugate, cat. no. 8889, Cell Signaling Technology, Inc., 1:1,000 dilution) for $1 \mathrm{~h}$ at room temperature. The cells were stained with DAPI and observed under a fluorescence microscope (Olympus Corp.).

Transwell assay. Transwell chambers (8- $\mu$ m-pore; Corning Inc.) were used to evaluate cell migration and invasion. Matrigel was applied in the invasion assay. Briefly, after transfection or different treatment conditions for $48 \mathrm{~h}, 2 \times 10^{4}$ cells were resuspended in $200 \mu \mathrm{l}$ of serum-free medium and added to the upper chamber. Then, medium with $10 \%$ FBS was added to the opposite (lower) chamber. After $24 \mathrm{~h}$, the cells remaining in the upper chamber were wiped away. The cells 
on the Transwell membrane were fixed and stained (by $4 \%$ paraformaldehyde and $0.1 \%$ crystal violet, respectively, for 15 min each at room temperature). Finally, the number of cells was counted in five random fields (magnification, x100; BX53 upright microscope; Olympus Corp.).

Wound-healing assay. PANC-1 cells were treated with AREG $(100 \mathrm{ng} / \mathrm{ml})$ alone (AREG), AREG combined with QNZ (20 $\mu \mathrm{M}$, AREG+QNZ), or normal $\mathrm{IgG}(100 \mathrm{ng} / \mathrm{ml}, \mathrm{NC})$ for $48 \mathrm{~h}$. A total of $5 \times 10^{5}$ cells were seeded in a 6 -well plate and grown to $90 \%$ confluence. A sterile $200-\mu \mathrm{l}$ pipette tip was used to form a constant width gap. After removal of cell debris, $1 \mathrm{ml}$ of serum-free medium was added to each well. The scratched areas were imaged at $0,24,48$, and $72 \mathrm{~h}$ using a DP-73 scientific camera on a phase-contrast microscope (Olympus Corp.). The cell-free area was calculated using ImageJ software (version 1.48v; National Institutes of Health), and the percentage of the original cell-free zone at each time-point was used to evaluate the speed of wound healing. The values were the means of three independent experiments.

Lentivirus construction and transduction. Short hairpin RNA (shRNA) targeting AREG was designed and synthesized by Shanghai GeneChem Co., Ltd., and used to construct the experimental plasmids (pGV248/AREG-shRNA); the shRNA was inserted into an AgeI- and EcoRI-linearized pGV248. The negative control vector (pGV248/control-shRNA) was constructed similarly by inserting an unrelated shRNA sequence. All inserted sequences were verified by sequencing. To generate stable cell lines, recombinant lentiviruses (namely, LV-AREG and LV-con) were generated and subsequently used to infect AsPC-1 cells.

Orthotopic model of pancreatic cancer. Twelve six- to seven-week-old female athymic nude mice (BALB/c nu/nu) were randomly assigned to 2 groups. Six mice with LV-AREG cells were distributed to the experimental group, while the other 6 mice with LV-con cells were in the control group. In detail, the mice were anaesthetized and placed in a supine position; the abdomen was disinfected with $70 \%$ alcohol, and then, an incision of $<1 \mathrm{~cm}$ was performed to expose the pancreas. AsPC-1 cells $\left(2 \times 10^{6}\right)$ were injected into the tail of the pancreas, and the wound was sutured. The mice were fed in SPF conditions and weighed twice weekly. The mice were sacrificed by $\mathrm{CO}_{2}$ asphyxiation on the 39th day after the injection. The pancreas was removed, and the tumours were weighed. The stomach, spleen, liver, intestine and kidney were examined for the presence of metastases. This study was conducted with the approval of the Institutional Animal Care and Use Committee of Peking Union Medical College Hospital and was in accordance with the National Policy on Use of Laboratory Animals.

Statistical analysis. All data were sorted and analysed using SPSS software for Windows, version 17.0 (SPSS, Inc.). The results are expressed as the mean \pm SD. Significance was evaluated by performing Student's t-tests or one-way analysis of variance (ANOVA) with Tukey's post hoc test. A P-value $<0.05$ was considered to indicate a statistically significant difference.

\section{Results}

EGFR and AREG expression in pancreatic cancer cells. To investigate EGFR and AREG expression in pancreatic cancer cell lines, RT-qPCR, western blot analysis and ELISA were performed. These analyses revealed that EGFR expression was significantly high in the AsPC-1 cells and BxPC-3 cells compared with that in MIA PaCa-2 cells (Fig. 1A and B). AREG expression was significantly high in the AsPC-1 cells, BxPC-3 cells and MIA PaCa-2 cells, compared with that in PANC-1 cells (Fig. 1C and D). AsPC-1 (high EGFR expression and high AREG expression) and PANC-1 cells (high EGFR expression and low AREG expression) were selected for the subsequent loss-of-function and gain-of-function experiments. To characterize the biological effects of AREG, AREG siRNAs were used to suppress the endogenous expression of AREG in AsPC-1 cells. Three different AREG siRNAs and 1 control siRNA were used. The results revealed that siAR-390 was most effective in inhibiting AREG mRNA (65\% reduction) and protein (64\% reduction) expression in AsPC-1 cells (Fig. S1). Therefore, siAR-390 was used in the subsequent experiments.

AREG facilitates the migration and invasion of pancreatic cancer cells. Transwell assays were performed to monitor whether AREG could affect pancreatic cancer cell migration and invasion. The results revealed a nearly $50 \%$ reduction in cell migration and 47\% reduction in cell invasion in AREG siRNA-transfected AsPC-1 cells ( $\mathrm{P}<0.05$ and $\mathrm{P}<0.01$, Fig. $2 \mathrm{~A})$. Knockdown of AREG significantly decreased the migration ability of BxPC-3 cells ( $<<0.01$, Fig. S2). To confirm the involvement of AREG in pancreatic cancer cell migration and invasion, recombinant human AREG treatment was used. Exposure to exogenous AREG $(100 \mathrm{ng} / \mathrm{ml})$ significantly promoted the migration and invasion of the PANC-1 cells $(\mathrm{P}<0.05$ and $\mathrm{P}<0.01$, Fig. 2B). It was revealed that AREG was expressed in activated pancreatic stellate cells (PSCs), and co-culture with PSCs significantly increased the migration and invasion of PANC-1 cells (Fig. S3). The results revealed that AREG facilitated the migration and invasion of pancreatic cancer cells.

AREG promotes EMT in pancreatic cancer cells. E-cadherin and ZO-1 expression was upregulated, however, vimentin, $\beta$-catenin, Snail, Slug, and ZEB-1 levels were downregulated in the AREG siRNA-transfected AsPC-1 cells (Fig. 3A). Knockdown of AREG upregulated the expression of E-cadherin and downregulated the expression of $\beta$-catenin and vimentin in BxPC-3 cells (Fig. S2). As anticipated, these proteins displayed the opposite expression profiles in the AREG-treated $(100 \mathrm{ng} / \mathrm{ml})$ PANC-1 cells, whereas ZEB-1 expression exhibited no evident change (Fig. 3B). The changes in the expression of E-cadherin and vimentin induced by AREG were also examined by immunofluorescence. The results revealed the upregulated expression of E-cadherin and the downregulated expression of vimentin in AREG siRNA-transfected AsPC-1 cells. In contrast, the downregulated expression of E-cadherin and the upregulated expression of vimentin were observed in AREG-treated PANC-1 cells (Fig. 3C). 

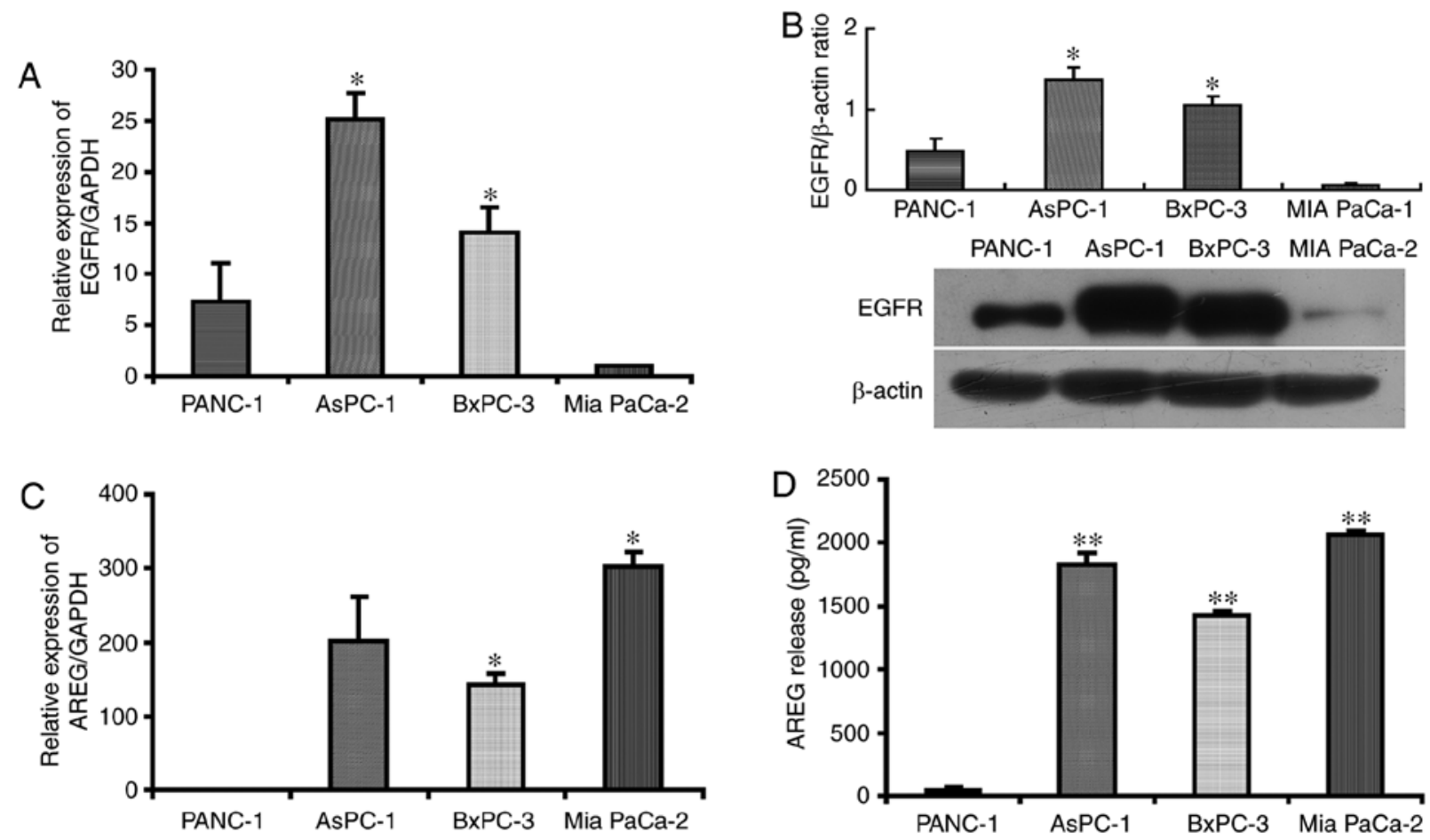

Figure 1. EGFR and AREG expression in pancreatic cancer cells. (A) The mRNA expression of EGFR was examined by RT-qPCR. (B) Western blotting was performed to determine the protein levels of EGFR in a panel of pancreatic cancer cell lines. Equal amounts of protein were subjected to immunoblotting using the EGFR and $\beta$-actin antibodies. (C) The mRNA expression of AREG was examined by RT-qPCR. (D) AREG ELISA was performed using conditioned medium collected from PANC-1, AsPC-1, Bxpc-3, and Mia PaCa-2 cells. The data represent the mean \pm SD of at least three independent experiments. "P<0.05, ${ }^{* *} \mathrm{P}<0.01$. EGFR, epidermal growth factor receptor; AREG, amphiregulin; ELISA, enzyme-linked immunosorbent assay.
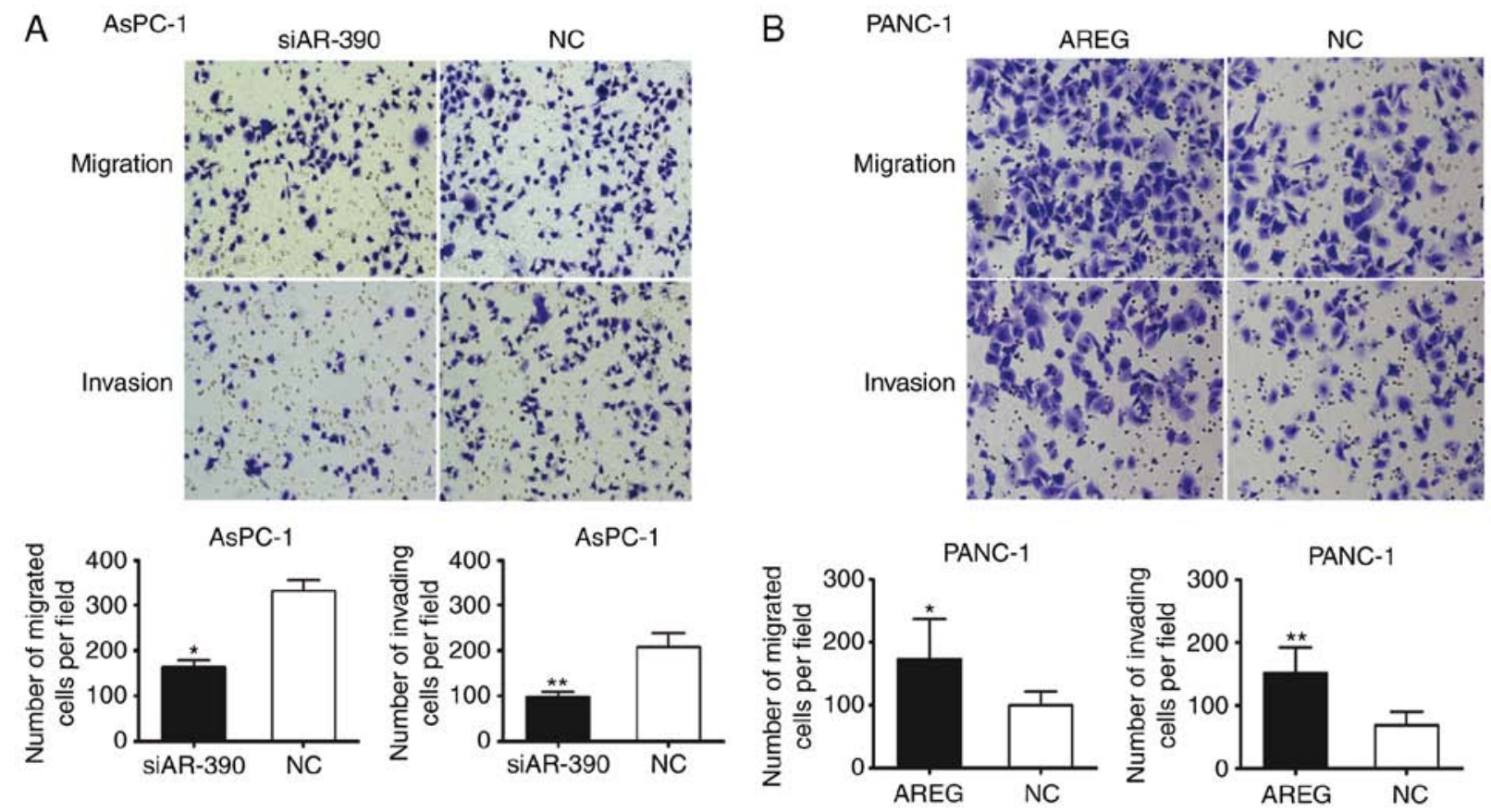

Figure 2. AREG facilitates the migration and invasion of pancreatic cancer cells. Transwell assays were performed to analyse cell migration and invasion. (A) Knockdown of AREG reduced the migration and invasion in AsPC-1 cells. AsPC-1 cells were transfected with AREG siRNA (siAR-390) or control siRNA (NC). (B) Exogenous AREG treatment induced the migration and invasion in PANC-1 cells. PANC-1 cells were exposed to AREG (100 ng/ml, AREG), or normal $\mathrm{IgG}(100 \mathrm{ng} / \mathrm{ml}, \mathrm{NC})$ for $48 \mathrm{~h}$. The data represent the mean $\pm \mathrm{SD}$ of at least three independent experiments, ${ }^{*} \mathrm{P}<0.05,{ }^{* *} \mathrm{P}<0.01$. AREG, amphiregulin.

AREG activates the EGFR/ERK signalling pathway in pancreatic cancer cells. To further explore the upstream signalling that may be responsible for AREG-induced EMT, the phosphorylation of EGFR, ERK, AKT and STAT3 was evaluated by performing western blot analyses. The phosphorylation levels of EGFR, ERK, AKT and STAT3 levels were 

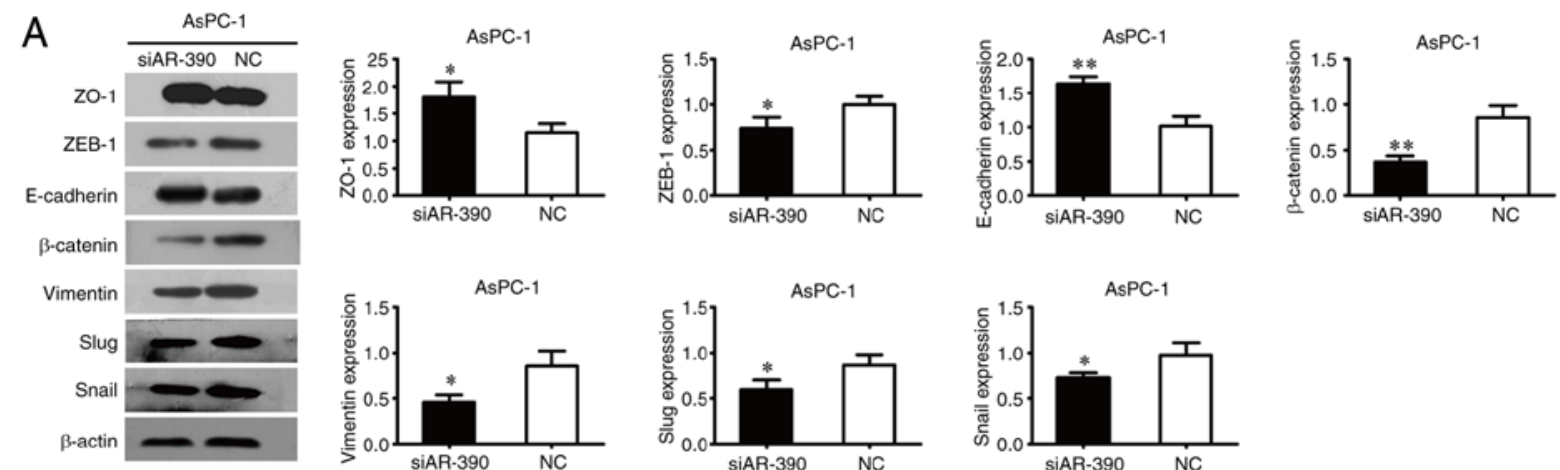

B
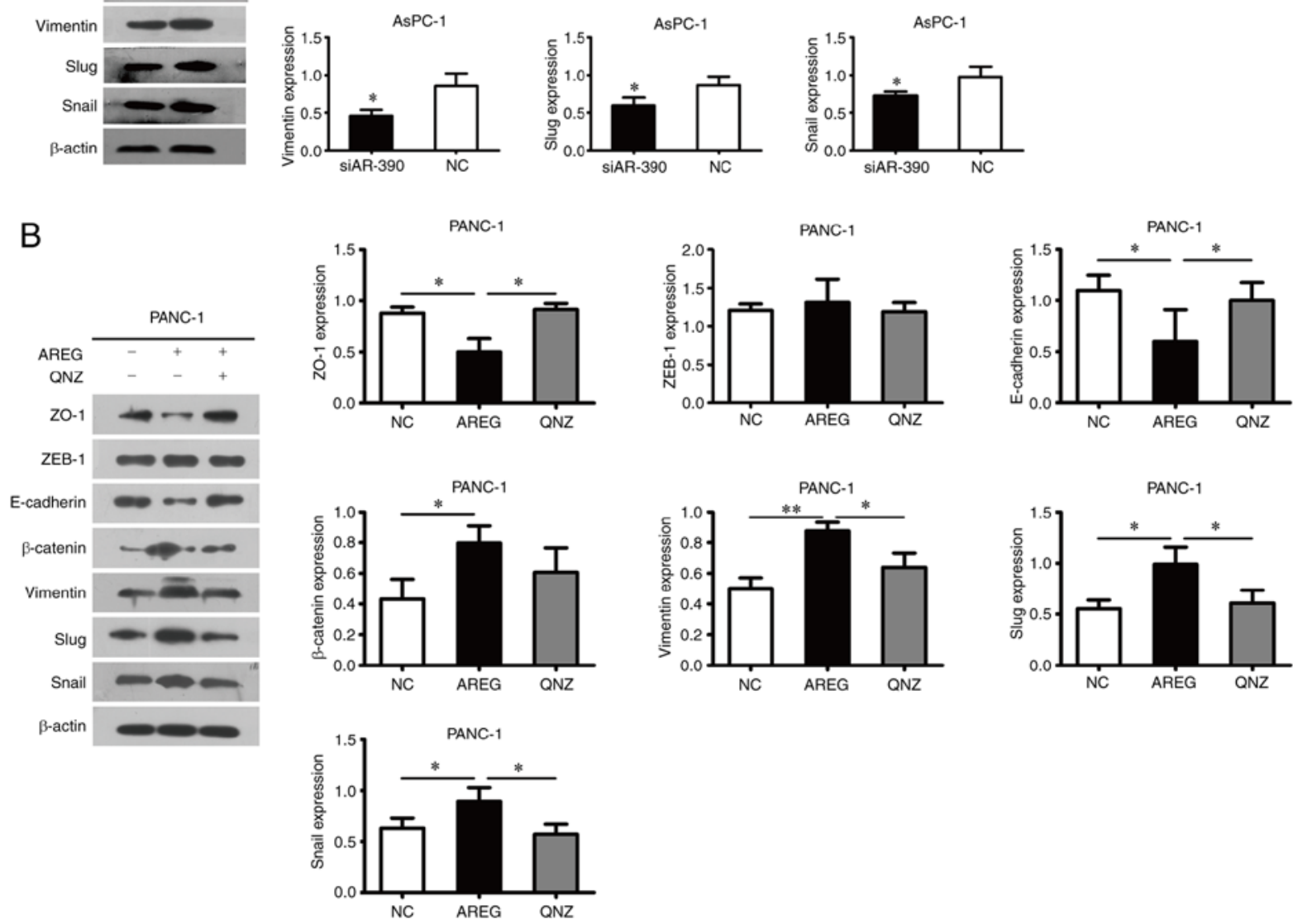

C

AsPC-1

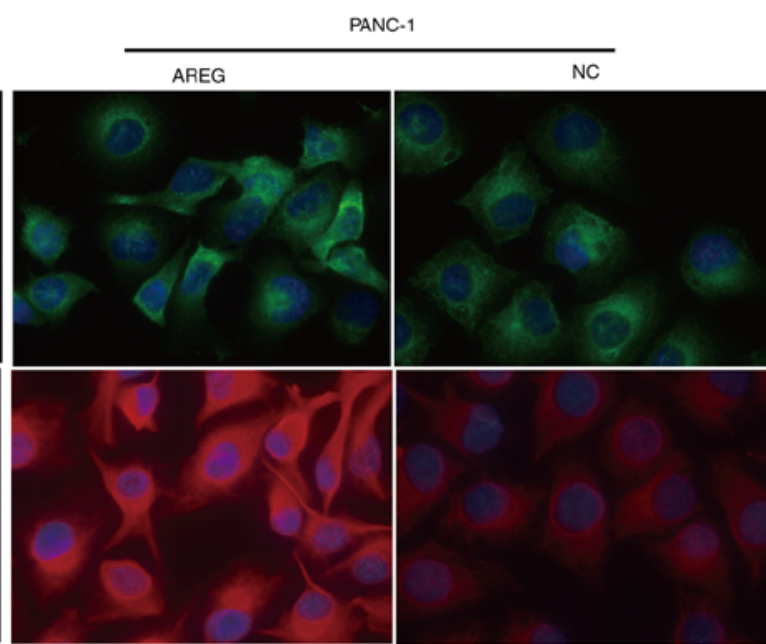

Figure 3. AREG promotes EMT in pancreatic cancer cells. (A) Western blot results of the EMT-related proteins from AsPC-1 cells transfected with AREG siRNA (siAR-390) or control siRNA (NC). (B) Western blot results of the EMT-related proteins derived for PANC-1 cells treated with AREG (100 ng/ml) alone (AREG), AREG combined with QNZ (the selective NF-אB inhibitor, $20 \mu \mathrm{M}$, AREG+QNZ), or normal IgG (100 ng/ml, NC). (C) Immunofluorescence staining results of E-cadherin and vimentin in AsPC-1 and PANC-1 cells. Magnification, x400. AREG, amphiregulin; EMT, epithelial-mesenchymal transition. The bars represent the mean $\pm \mathrm{SD}$ of triplicate analyses. ${ }^{*} \mathrm{P}<0.05,{ }^{* *} \mathrm{P}<0.01$.

downregulated in the AREG siRNA-transfected AsPC-1 cells (Fig. 4A). As anticipated, the exogenous treatment of AREG upregulated the phosphorylation levels of EGFR,ERK, AKT and STAT3 to varying degrees in PANC-1 cells. It was revealed that the small molecule inhibitors of EGFR (PD153035) suppressed the AREG-induced ERK, AKT and STAT3 phosphorylation (Fig. 4B). The expression levels of total EGFR, ERK, AKT, and STAT3 were not significantly altered in pancreatic cancer 


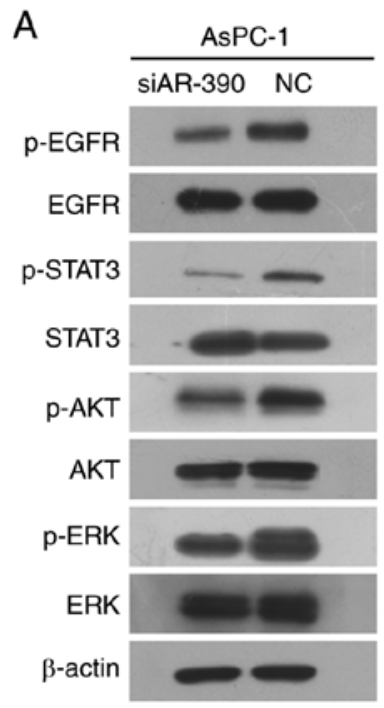

B

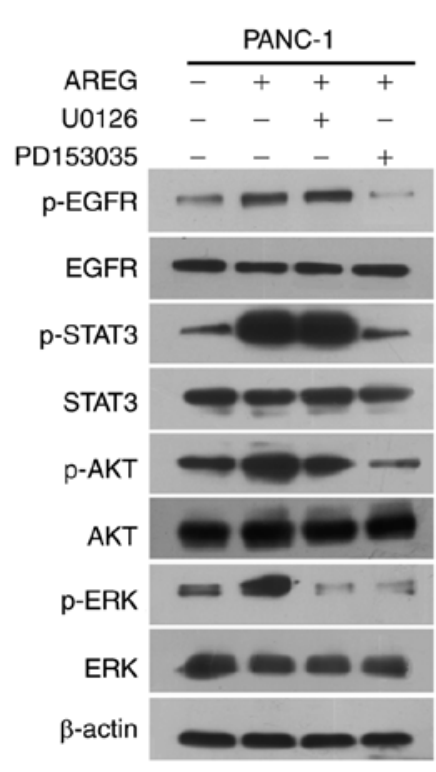

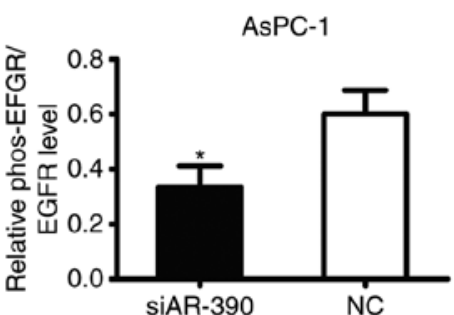

AsPC-1

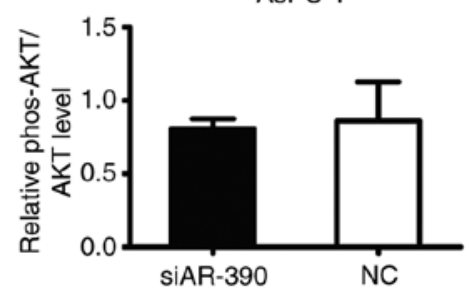

PANC-1

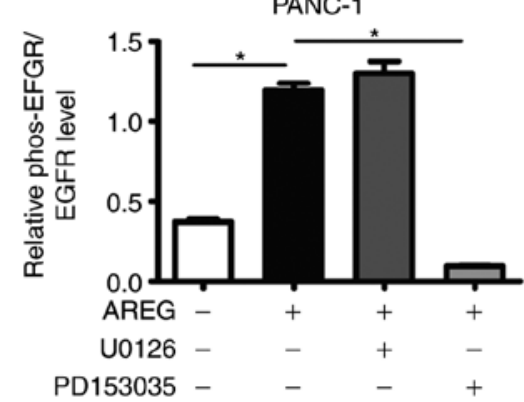

PANC-1

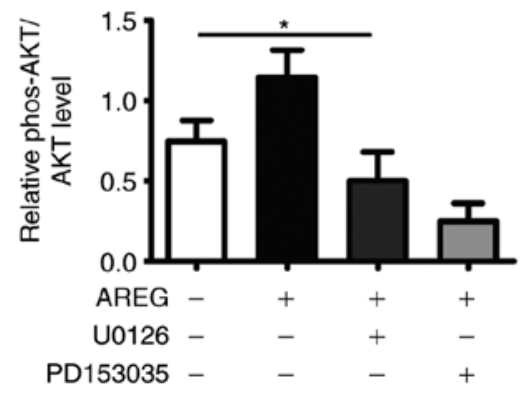

AsPC-1

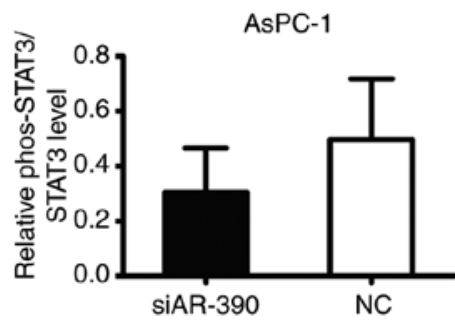

AsPC-1

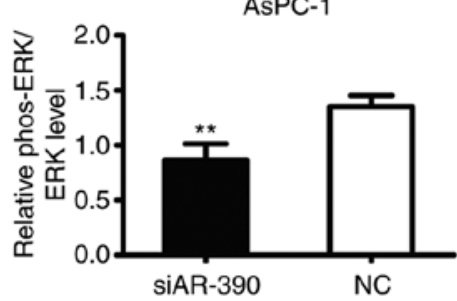

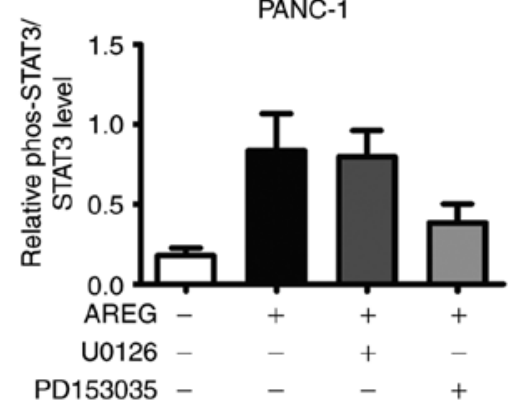

PANC-1

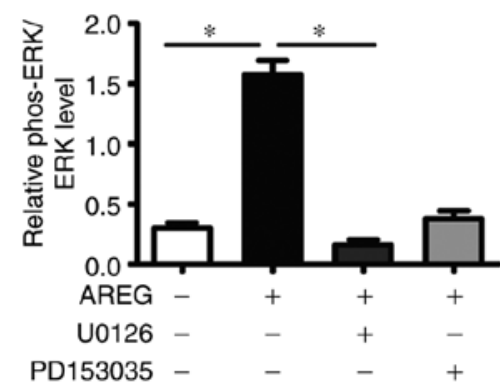

C

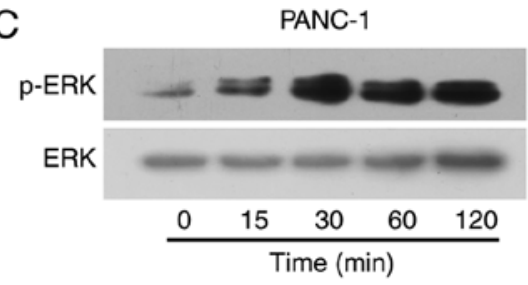

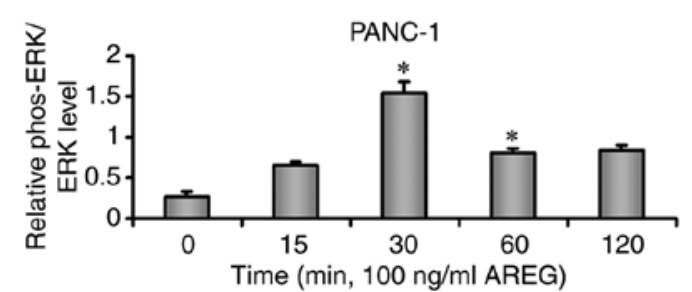

Figure 4. AREG activates the EGFR/ERK signalling pathway in pancreatic cancer cells. (A) Phosphorylation and total protein expression levels of EGFR, STAT3, AKT, and ERK in AsPC-1 cells transfected with AREG siRNA (siAR-390) or control siRNA (NC). (B) In PANC-1 cells, the exogenous treatment of AREG induced EGFR signalling as revealed by the varying degrees of activation of the p-ERK, p-AKT and p-STAT3 levels. The enhancement effect was blocked by PD153035 (an inhibitor of EGF receptor tyrosine kinase, $5 \mu \mathrm{M}$ ) or U0126 (an inhibitor of MEK1/2, 20 $\mu \mathrm{M}$ ). (C) Activation of ERK in response to AREG in PANC-1 cells. AREG stimulation resulted in a significant induction of p-ERK, which stabilized at 30 min. Graphs are presented as the relative density of the phosphoprotein vs. the total protein. ${ }^{*} \mathrm{P}<0.05$ compared with the control untreated cells at 0 min. ${ }^{*} \mathrm{P}<0.05$, ${ }^{* *} \mathrm{P}<0.01$. AREG, amphiregulin; EGFR, epidermal growth factor receptor.

cells (Fig. 4A and B). The results revealed a significant decrease in phospho-ERK in siRNA-transfected AsPC-1 cells $(\mathrm{P}<0.01)$ and a significant increase in phospho-ERK in exogenous AREG-treated PANC-1 cells $(\mathrm{P}<0.05)$. To further characterize the effect of AREG on ERK activation, ERK phosphorylation was examined at various time-points after AREG stimulation; the peak phosphorylated ERK level occurred 30 min after AREG stimulation (Fig. 4C). The small molecule inhibitor of MEK1/2 (U0126) significantly reduced the phosphorylation level of ERK in exogenous AREG-treated PANC-1 cells. 
A

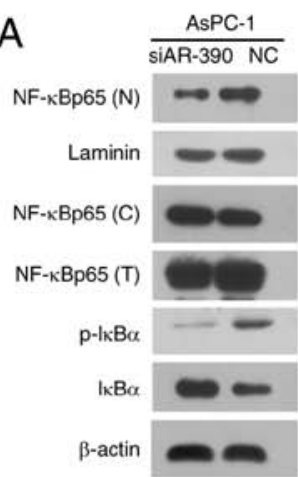

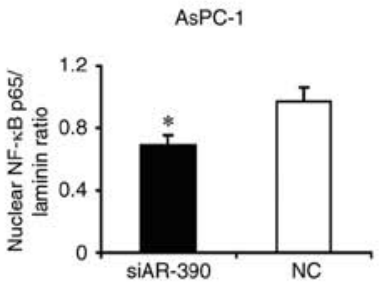

C

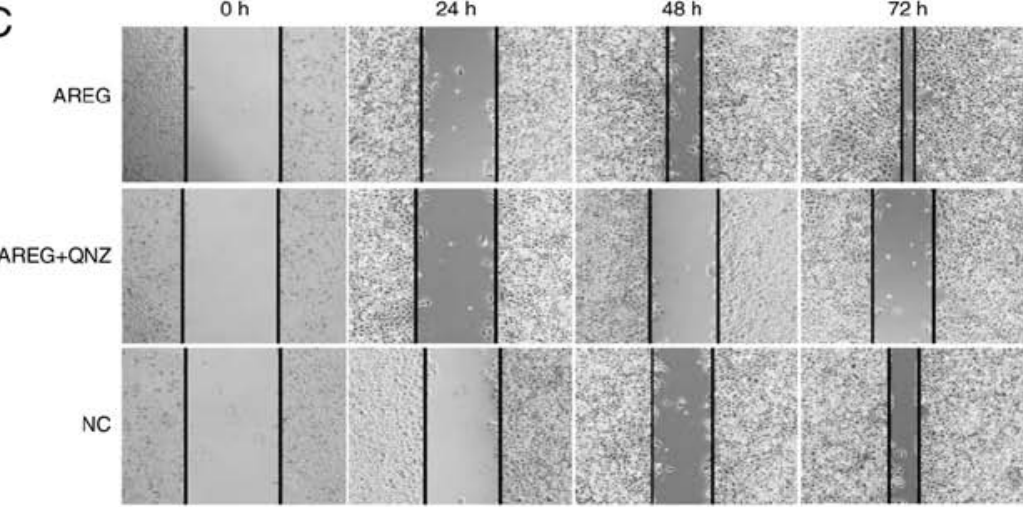

D
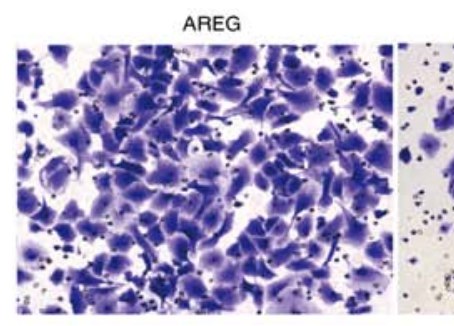

AREG+QNZ

NC

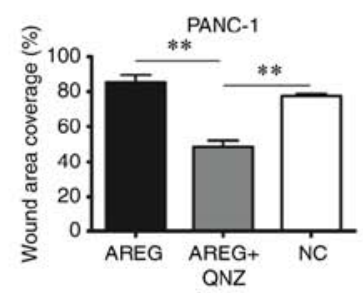

Figure 5. The NF- $\mathrm{B}$ pathway is involved in AREG-induced migration and invasion of pancreatic cancer cells. (A) Representative images and analysis of western blots for $\mathrm{I} \kappa \mathrm{B} \alpha$, p-IкB $\alpha$, nuclear $\mathrm{p} 65$ in AsPC-1 cells transfected with AREG siRNA (siAR-390) or control siRNA (NC). (B) Representative images and analysis of western blots for I $\mathrm{B} \alpha, \mathrm{p}-\mathrm{I} \kappa \mathrm{B} \alpha$, nuclear p65 in PANC-1 cells treated with AREG (100 ng/ml), U0126 (20 $\mu \mathrm{M}), \mathrm{PD} 153035$ (5 $\mu \mathrm{M})$, and normal IgG (100 ng/ml, NC). (C) Wound-healing assay. QNZ inhibited the migratory ability of PANC-1 cells induced by AREG. (D) Transwell assay. QNZ abolished the invasive properties of PANC-1 cells induced by AREG. PANC-1 cells treated with AREG (100 ng/ml) alone (AREG), AREG combined with QNZ (20 $\mu$ M, AREG+QNZ), or normal IgG $(100 \mathrm{ng} / \mathrm{ml}, \mathrm{NC})$. The data represent the mean $\pm \mathrm{SD}$ of at least three independent experiments, ${ }^{*} \mathrm{P}<0.05$, ${ }^{* *} \mathrm{P}<0.01$. AREG, amphiregulin.

Inhibition of the $N F-\kappa B$ signalling pathway suppresses AREG-induced cell migration, invasion and EMT in pancreatic cancer cells. Previous studies have suggested that NF- $\kappa \mathrm{B}$ plays an essential role in the induction and maintenance of EMT $(19,20)$. We proposed that the role of AREG-induced pancreatic cancer cell migration, invasion and EMT may be through regulation of the NF- $\kappa$ B signalling pathway. To evaluate this possibility, the nuclear accumulation level of NF- $\mathrm{KB} / \mathrm{p} 65$ and the phosphorylation level of I $\mathrm{K} B \alpha$ were analysed by western blot analysis. It was revealed that the nuclear accumulation level of NF- $\mathrm{KB} / \mathrm{p} 65$ and the phosphorylation level of I $\kappa \mathrm{B} \alpha$ were significantly decreased in AREG siRNA-transfected AsPC-1 cells compared with the siRNA control group $(\mathrm{P}<0.05$, Fig. 5A). In contrast, the nuclear accumulation level of NF- $\mathrm{BB} / \mathrm{p} 65$ and the phosphorylation level of IкB $\alpha$ were significantly increased in AREG-treated PANC-1 cells. U0126 attenuated the AREG-promoted nuclear accumulation of NF- $\mathrm{KB} / \mathrm{p} 65$ in PANC-1 cells $(\mathrm{P}<0.05$, Fig. 5B). Furthermore, the role of the
Table I. Incidence of metastasis in a pancreatic cancer orthotopic model.

\begin{tabular}{lcc}
\hline Metastatic sites & LV-AREG $(\mathrm{n}=5)$ & LV-con $(\mathrm{n}=6)$ \\
\hline Liver & 0 & 3 \\
Spleen & 1 & 2 \\
Intestine & 0 & 1 \\
Stomach & 0 & 1 \\
Kidney & 1 & 1
\end{tabular}

AREG, amphiregulin .

NF- $\mathrm{kB}$ signalling pathway in AREG-induced cell migration, invasion and EMT in pancreatic cancer cells was investigated using the selective NF- $\mathrm{KB}$ inhibitor QNZ. PANC-1 cells were pre-treated with $20 \mu \mathrm{M}$ QNZ for $1 \mathrm{~h}$, followed 

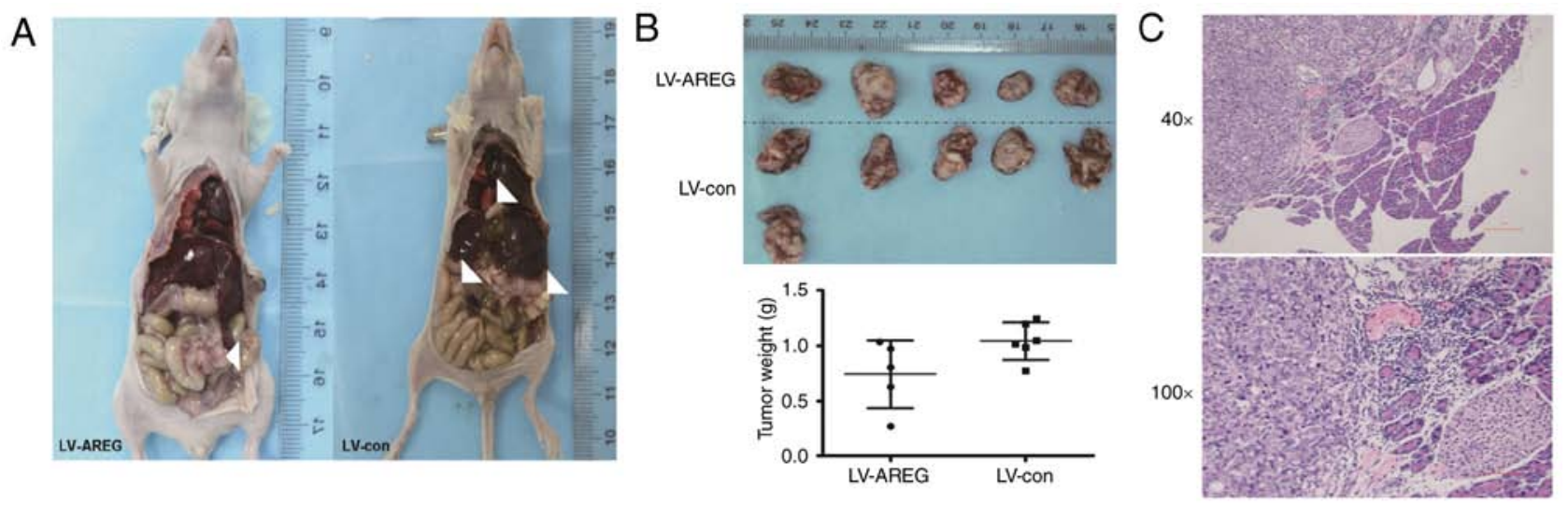

Figure 6. Orthotopic model of pancreatic cancer. (A) Representative image of macroscopic metastasis in mice injected with AsPC-1 cells. (B) Representative image of the tumours that formed in the pancreas. (C) H\&E staining confirmed pancreatic tumour development in mice injected with AsPC-1 cells. AREG, amphiregulin.

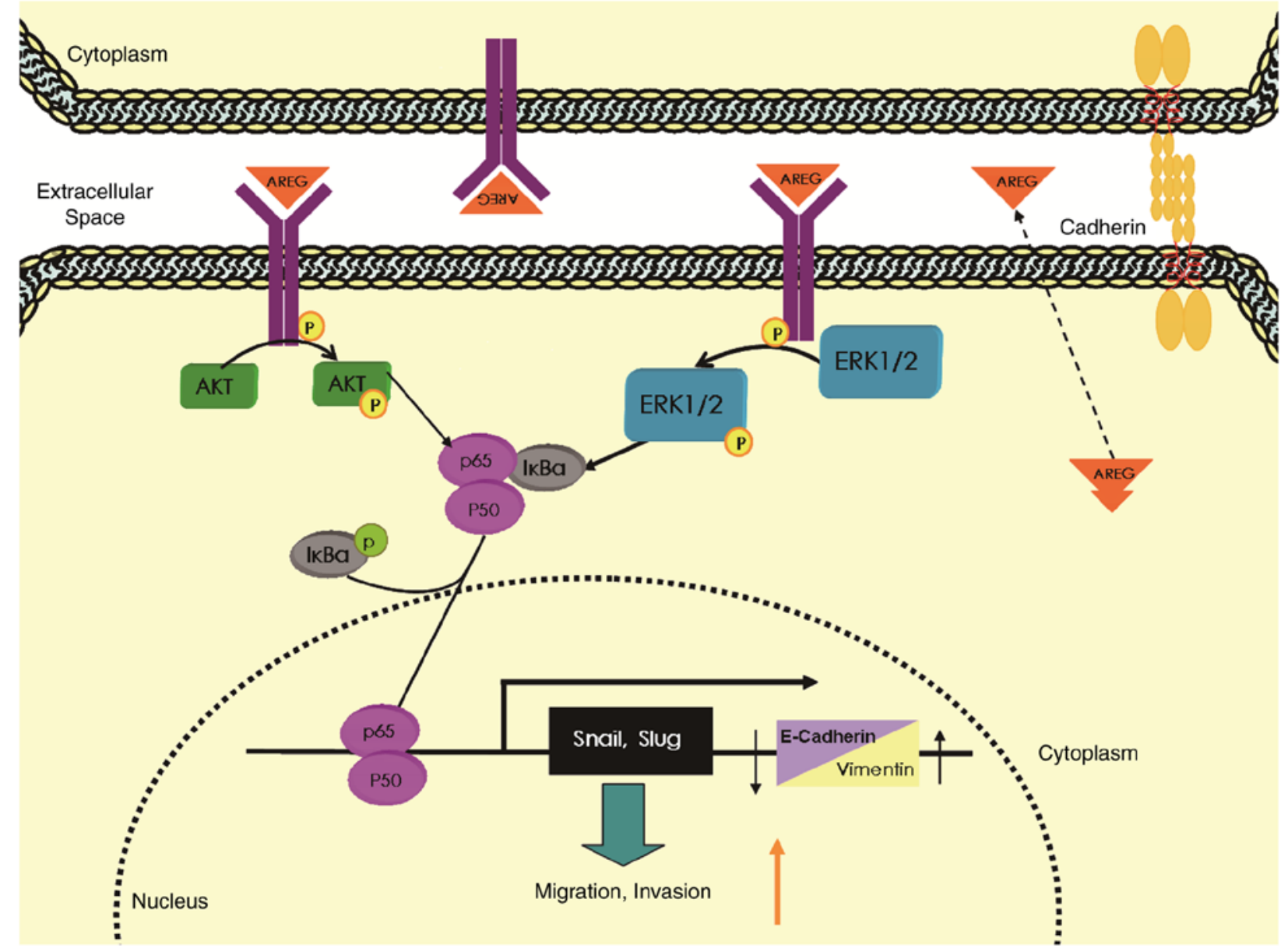

Figure 7. Diagram illustrating the signalling pathways implicated in AREG-induced EMT in human pancreatic cancer cells. AREG induces the nuclear accumulation of NF- $\mathrm{kB} / \mathrm{p} 65$ through the EGFR/ERK signalling pathways. NF- $\mathrm{\kappa B}$ mediates the AREG-induced cell migration and invasion by regulating EMT in human pancreatic cancer cells. Blockade of these pathways using different inhibitors decreased EMT in pancreatic cancer cells. Refer to the Discussion section for further explanation. AREG, amphiregulin; EMT, epithelial-mesenchymal transition; EGFR, epidermal growth factor receptor.

by incubation with $100 \mathrm{ng} / \mathrm{ml}$ AREG for $48 \mathrm{~h}$. Based on the wound-healing assay, QNZ significantly inhibited the migratory ability of PANC-1 cells induced by AREG at $72 \mathrm{~h}$ $(\mathrm{P}<0.01$, Fig. 5C). Transwell assay results revealed that $\mathrm{QNZ}$ abolished the invasive properties of PANC-1 cells induced by AREG ( $\mathrm{P}<0.01$, Fig. 5D). According to the western blot analysis, pre-treatment of PANC-1 cells with QNZ resulted in the upregulation of E-cadherin and $\mathrm{ZO}-1$ and the downregulation of vimentin, Slug, and Snail (Fig. 3B). All of the aforementioned results indicated that inhibition of the $\mathrm{NF}-\kappa \mathrm{B}$ signalling pathway suppressed AREG-induced cell migration, invasion and EMT in pancreatic cancer cells. 
Orthotopic model of pancreatic cancer. The survival rate in our model was $91.7 \%$; one mouse in the LV-AREG group died the day after the injection. All mice in the LV-AREG and LV-con groups exhibited a tumour at the site of the injection of cells into the pancreas tail. The incidence of regional and distant metastasis was lower in the LV-AREG group compared with the LV-con group (Table I; Fig. 6A). Macroscopically, the tumours appeared as firm, white, irregular masses. There had been a downward trend in tumour growth with AREG silencing in the orthotopic model of pancreatic cancer $(0.74 \pm 0.31 \mathrm{~g}$ vs. $1.04 \pm 0.17 \mathrm{~g})$; however, no significant differences were revealed between the LV-AREG group and LV-con groups $(\mathrm{P}>0.05$, Fig. 6B). H\&E staining confirmed pancreatic tumour development in mice (Fig. 6C).

\section{Discussion}

Pancreatic cancer is one of the leading causes of cancer-related mortality worldwide. The drug-resistant characteristics of pancreatic cancer cells result in their partial responses to traditional cytotoxic chemotherapy. The EMT phenotype is emerging as an important feature of drug-resistant pancreatic cancer cells (2-4). EMT modifies the adhesion molecules expressed by the epithelial cells, allowing the cells to adopt migratory and invasive behaviours (21).

AREG gene overexpression has been observed in a wide variety of human cancer tissues (22). Willmarth et al (11) reported that AREG upregulated numerous genes involved in cell motility and invasion in the human mammary epithelial cell line MCF10A. Liu et al (23) revealed that AREG promoted cancer cell motility in osteosarcoma and upregulated the expression of ICAM-1 through the EGFR/PI3K/Akt/NF- $\mathrm{BB}$ signalling pathway. Loss-of-function and gain-of-function experiments have revealed that AREG modulates the cell migration and invasion of pancreatic cancer cells in vitro. In an orthotopic model of pancreatic cancer, AREG silencing was revealed to be related to smaller tumour sizes and reduced metastatic ability. The present data are in line with the results of previous studies, suggesting that AREG plays a critical role in the motility and metastasis of pancreatic cancer cells.

EMT may be a key process for the acquisition of capabilities required for metastasis $(7,21)$. The functional decrease in E-cadherin is among the hallmarks of EMT. AREG has been reported to stimulate ovarian cancer cell invasion by downregulating the expression level of E-cadherin (10). AREG was revealed to markedly decrease E-cadherin expression in psoriatic lesions from both AREG-transgenic mice and individuals with psoriasis (24). Consistent with these studies, in the present study, knockdown of AREG upregulated the expression of E-cadherin and downregulated the expression of $\beta$-catenin and vimentin in AsPC- 1 and $\mathrm{BxPC}-3$ cells. The loss of cell polarity complexes and adhesion complexes leads to the failure to maintain epithelial cell polarity, induces EMT and enhances cell invasive potential (25). Kleeff et al have revealed that ZO-1 was significantly increased in pancreatic cancer (26). In the present study, the inhibition of AREG induced ZO-1 expression in pancreatic cancer cells. Transcriptional repression mediated by factors from the Snail, ZEB and basic helix-loop-helix families is a basic mechanism of the dynamic silencing of the E-cadherin promoter CDH1 (27). Snail was revealed to suppress the expression of E-cadherin and induce the expression of the mesenchymal markers fibronectin and ZEB-1 in tumour cells $(28,29)$. The knockdown of Slug in glioblastoma cells decreased invasion and increased survival in a mouse intracranial human glioblastoma transplantation model (30). Consistently, in the present study, AREG increased the levels of Snail and Slug. Thus, AREG may be involved in EMT in pancreatic cancer cells.

Numerous cellular pathways have been implicated in the regulation of the EMT process in pancreatic cancer $(6,31)$. The present results revealed that AREG induced the activation of the ERK, AKT and STAT3 pathways, although the activation of the ERK pathway was the most marked. NF- $\kappa \mathrm{B}$ is constitutively active in different cancers. It was revealed that AREG induced the activation of $\mathrm{I} \kappa \mathrm{B} \alpha$ and $\mathrm{NF}-\kappa \mathrm{B}$ in pancreatic cancer cells. The pharmacological inhibition of EGFR or ERK attenuated the effects of the AREG-induced nuclear accumulation of NF- $\kappa \mathrm{B}$. Thus, the EGFR/ERK/NF- $\kappa \mathrm{B}$ axis was likely involved in AREG-mediated pancreatic cancer cell migration, invasion and EMT.

The stroma plays a dynamic role in tumour cell proliferation, invasion and metastasis in pancreatic cancer (32). PSCs play a critical role in the tumour desmoplasticity of pancreatic cancer $(33,34)$. PSCs were revealed to promote EMT in pancreatic cancer cells and facilitate BxPC-3 cell invasion $(35,36)$. The expression of AREG by PSCs and its roles in the tumour microenvironment remains elusive. In the present study, it was revealed that AREG was expressed in activated PSCs, and co-culture with PSCs significantly increased the migration and invasion of PANC-1 cells. However, using an anti-human AREG-neutralizing antibody did not decrease the migration and invasion abilities of PANC-1 cells, indicating that AREG was not the main inducer of PANC-1 cell migration in PSC secretions. In future research, the role of how AREG affects the biological characteristics of PSCs requires further thorough investigation. The animal experiment was originally designed to verify whether knockdown of AREG would affect tumorigenicity in vivo. Although there was a trend in reduced tumour burden with AREG silencing, no significant differences were revealed between the LV-AREG group and LV-con groups $(\mathrm{P}>0.05)$. In a future experimental design, appropriate increasing of the sample size of animal experiments will be considered in order to obtain more sample sizes for subsequent experiments and render the research results more complete.

In conclusion, the EGFR ligand AREG plays an important role in $\mathrm{NF}-\kappa \mathrm{B}-$ mediated migration and invasion as well as EMT in pancreatic cancer cells by activating the EGFR/ERK/NF- $\mathrm{B}$ signalling pathway (Fig. 7). AREG may be a promising target for the treatment of pancreatic cancer.

\section{Acknowledgements}

Not applicable.

\section{Funding}

This study was supported by the National Natural Science Foundation of China (31471366), the Chinese Academy of Medical Sciences (CAMS) Initiative for Innovative Medicine 
(CAMS-I2M) 2016-I2M-1-002 and the National Natural Science Foundation of China (81502625). The study sponsors did not play any role in the study design, collection, analysis, interpretation of data and in the writing of the manuscript.

\section{Availability of data and material}

The datasets used during and/or analysed during the present study are available from the corresponding author on reasonable request.

\section{Authors' contributions}

LiW was mainly responsible for the research and writing the manuscript. LilW assisted in selecting the specimens and performing quantitative real-time PCR and RNA interference assays and the orthotopic model of pancreatic cancer. HZ contributed to the immunofluorescence and Transwell assays and lentivirus construction and transduction. JL assisted with the western blot assays and ELISA. ZZ performed the statistical analyses. HW supplied the technical analysis and performed the manuscript revisions. ZL conceived and designed the whole study. All authors read and approved the final manuscript and agree to be accountable for all aspects of the research in ensuring that the accuracy or integrity of any part of the work are appropriately investigated and resolved.

\section{Ethics approval and consent to participate}

The present study was conducted with the approval of the Institutional Animal Care and Use Committee of Peking Union Medical College Hospital and was in accordance with the National Policy on Use of Laboratory Animals.

\section{Patient consent for publication}

Not applicable.

\section{Competing interests}

The authors declare that they have no competing interests.

\section{References}

1. Siegel RL, Miller KD and Jemal A: Cancer statistics, 2019. CA Cancer J Clin 69: 7-34, 2019.

2. Amrutkar M and Gladhaug I: Pancreatic cancer chemoresistance to gemcitabine. Cancers 9: 157, 2017.

3. Du B and Shim JS: Targeting Epithelial-mesenchymal transition (EMT) to overcome drug resistance in cancer. Molecules 21: pii: E965, 2016.

4. Arumugam T, Ramachandran V, Fournier KF, Wang H, Marquis L, Abbruzzese JL, Gallick GE, Logsdon CD, McConkey DJ and Choi W: Epithelial to mesenchymal transition contributes to drug resistance in pancreatic cancer. Cancer Res 69: 5820-5828, 2009.

5. Bronsert P, Enderle-Ammour K, Bader M, Timme S, Kuehs M, Csanadi A, Kayser G, Kohler I, Bausch D, Hoeppner J,et al: Cancer cell invasion and EMT marker expression: A three-dimensional study of the human cancer-host interface. J Pathol 234: 410-422, 2014.

6. Wang $\mathrm{L}$, Wu H, Wang L, Zhang H, Lu J, Liang Z and Liu T: Asporin promotes pancreatic cancer cell invasion and migration by regulating the epithelial-to-mesenchymal transition (EMT) through both autocrine and paracrine mechanisms. Cancer Lett 398: 24-36, 2017.
7. Rhim AD, Mirek ET, Aiello NM, Maitra A, Bailey JM, McAllister F, Reichert M, Beatty GL, Rustgi AK, Vonderheide RH, et al: EMT and dissemination precede pancreatic tumor formation. Cell 148: 349-361, 2012.

8. Fischer KR, Durrans A, Lee S, Sheng J, Li F, Wong ST, Choi H, El Rayes T, Ryu S, Troeger J, et al: Epithelial-to-mesenchymal transition is not required for lung metastasis but contributes to chemoresistance. Nature 527: 472-476, 2015.

9. Zheng X, Carstens JL, Kim J, Scheible M, Kaye J, Sugimoto H, Wu CC, LeBleu VS and Kalluri R: Epithelial-to-mesenchymal transition is dispensable for metastasis but induces chemoresistance in pancreatic cancer. Nature 527: 525-530, 2015.

10. So WK, Fan Q, Lau MT, Qiu X, Cheng JC and Leung PC: Amphiregulin induces human ovarian cancer cell invasion by down-regulating E-cadherin expression. FEBS Lett 588: 3998-4007, 2014.

11. Willmarth NE and Ethier SP: Autocrine and juxtacrine effects of amphiregulin on the proliferative, invasive, and migratory properties of normal and neoplastic human mammary epithelial cells. J Biol Chem 281: 37728-37737, 2006.

12. Thøgersen VB, Sorensen BS, Poulsen SS, Orntoft TF, Wolf H and Nex $\varnothing$ E: A subclass of HER1 ligands is a prognostic marker for survival in bladder cancer patients. Cancer Res 61: 6227-6233, 2001.

13. Ishikawa N, Daigo Y, Takano A, Taniwaki M, Kato T, Hayama S, Murakami H, Takeshima Y, Inai K, Nishimura H, et al: Increases of amphiregulin and transforming growth factor-alpha in serum as predictors of poor response to gefitinib among patients with advanced non-small cell lung cancers. Cancer Res 65: 9176-9184, 2005.

14. Jing C, Jin YH, You Z, Qiong Q and Jun Z: Prognostic value of amphiregulin and epiregulin mRNA expression in metastatic colorectal cancer patients. Oncotarget 7: 55890-55899, 2016.

15. Shinomiya H, Ito Y, Kubo M, Yonezawa K, Otsuki N, Iwae S, Inagaki $\mathrm{H}$ and Nibu KI: Expression of amphiregulin in mucoepidermoid carcinoma of the major salivary glands: A molecular and clinicopathological study. Hum Pathol 57: 37-44, 2016.

16. Wang L, Wu H, Wang L, Lu J, Duan H, Liu X and Liang Z: Expression of amphiregulin predicts poor outcome in patients with pancreatic ductal adenocarcinoma. Diagn Pathol 11: 60, 2016.

17. Zhang H, Wu H, Guan J, Wang L, Ren X, Shi X, Liang Z and Liu T: Paracrine SDF-1 $\alpha$ signaling mediates the effects of PSCs on GEM chemoresistance through an IL-6 autocrine loop in pancreatic cancer cells. Oncotarget 6: 3085-3097, 2015.

18. Livak KJ and Schmittgen TD: Analysis of relative gene expression data using real-time quantitative PCR and the 2(-Delta Delta C(T)) method. Methods 25: 402-408, 2001.

19. Gao S, Sun Y, Zhang X, Hu L, Liu Y, Chua CY, Phillips LM, Ren H, Fleming JB, Wang H, et al: IGFBP2 Activates the NF- $\mathrm{BB}$ pathway to drive epithelial-mesenchymal transition and invasive character in pancreatic ductal adenocarcinoma. Cancer Res 76: 6543-6554, 2016.

20. Nomura A, Majumder K, Giri B, Dauer P, Dudeja V, Roy S, Banerjee $S$ and Saluja AK: Inhibition of NF-kappa B pathway leads to deregulation of epithelial-mesenchymal transition and neural invasion in pancreatic cancer. Lab Invest 96: 1268-1278, 2016.

21. Nieto MA, Huang RY, Jackson RA and Thiery JP: EMT: 2016. Cell 166: 21-45, 2016.

22. Busser B, Sancey L, Brambilla E, Coll JL and Hurbin A: The multiple roles of amphiregulin in human cancer. Biochim Biophys Acta 1816: 119-131, 2011.

23. Liu JF, Tsao YT and Hou CH: Amphiregulin enhances intercellular adhesion molecule-1 expression and promotes tumor metastasis in human osteosarcoma. Oncotarget 6: 40880-40895, 2015.

24. Chung E, Cook PW, Parkos CA, Park YK, Pittelkow MR and Coffey RJ: Amphiregulin causes functional downregulation of adherens junctions in psoriasis. J Invest Dermatol 124: 1134-1140, 2005

25. Coradini D, Casarsa C and Oriana S: Epithelial cell polarity and tumorigenesis: New perspectives for cancer detection and treatment. Acta Pharmacol Sin 32: 552-564, 2011.

26. Kleeff J, Shi X, Bode HP, Hoover K, Shrikhande S, Bryant PJ, Korc M, Büchler MW and Friess H: Altered expression and localization of the tight junction protein ZO-1 in primary and metastatic pancreatic cancer. Pancreas 23: 259-265, 2001.

27. Peinado H, Olmeda D and Cano A: Snail, Zeb and bHLH factors in tumour progression: An alliance against the epithelial phenotype? Nat Rev Cancer 7: 415-428, 2007. 
28. Batlle E, Sancho E, Francí C, Domínguez D, Monfar M, Baulida J and García De Herreros A: The transcription factor snail is a repressor of E-cadherin gene expression in epithelial tumour cells. Nat Cell Biol 2: 84-89, 2000.

29. Guaita S, Puig I, Franc1 C, Garrido M, Dominguez D, Batlle E, Sancho E, Dedhar S, De Herreros AG and Baulida J: Snail induction of epithelial to mesenchymal transition in tumor cells is accompanied by MUC1 repression and ZEB1 expression. J Biol Chem 277: 39209-39216, 2002.

30. Yang HW, Menon LG, Black PM, Carroll RS and Johnson MD: SNAI2/Slug promotes growth and invasion in human gliomas. BMC Cancer 10: 301, 2010.

31. Liang C, Wang Z, Li YY, Yu BH, Zhang F and Li HY: miR-33a suppresses the nuclear translocation of $\beta$-catenin to enhance gemcitabine sensitivity in human pancreatic cancer cells. Tumor Biol 36: 9395-9403, 2015.

32. von Ahrens D, Bhagat TD, Nagrath D, Maitra A and Verma A: The role of stromal cancer-associated fibroblasts in pancreatic cancer. J Hematol Oncol 10: 76, 2017.

33. Duner S, Lopatko LJ, Ansari D, Gundewar C and Andersson R: Pancreatic cancer: The role of pancreatic stellate cells in tumor progression. Pancreatology 10: 673-681, 2010.
34. Vonlaufen A, Joshi S, Qu C, Phillips PA, Xu Z, Parker NR, Toi CS, Pirola RC, Wilson JS, Goldstein D and Apte MV: Pancreatic stellate cells: Partners in crime with pancreatic cancer cells. Cancer Res 68: 2085-2093, 2008.

35. Kikuta K, Masamune A, Watanabe T, Ariga H, Itoh $\mathrm{H}$, Hamada $\mathrm{S}$, Satoh K, Egawa S, Unno M and Shimosegawa T: Pancreatic stellate cells promote epithelial-mesenchymal transition in pancreatic cancer cells. Biochem Biophys Res Commun 403: 380-384, 2010.

36. Saito K, Sakaguchi M, Maruyama S, Iioka H, Putranto EW, Sumardika IW, Tomonobu N, Kawasaki T, Homma K and Kondo E: Stromal mesenchymal stem cells facilitate pancreatic cancer progression by regulating specific secretory molecules through mutual cellular interaction. J Cancer 9: 2916-2929, 2018.

(i) (3) This work is licensed under a Creative Commons Attribution-NonCommercial-NoDerivatives 4.0 International (CC BY-NC-ND 4.0) License. 